\title{
Temperature Prediction Model for Two-Phase Flow Multistage Fractured Horizontal Well in Tight Oil Reservoir
}

\author{
Ruiduo Zhang $\left(\mathbb{D}\right.$, Yonggang Duan $\mathbb{D}$, and Mingqiang Wei $\mathbb{D}^{\mathbb{D}}$ \\ State Key Laboratory of Oil and Gas Reservoir Geology and Exploitation, Southwest Petroleum University, Chengdu 610500, China \\ Correspondence should be addressed to Ruiduo Zhang; zhangruiduoswpu@163.com
}

Received 11 March 2021; Revised 11 April 2021; Accepted 19 April 2021; Published 15 June 2021

Academic Editor: Tianran Ma

Copyright (C) 2021 Ruiduo Zhang et al. This is an open access article distributed under the Creative Commons Attribution License, which permits unrestricted use, distribution, and reproduction in any medium, provided the original work is properly cited.

\begin{abstract}
Distributed temperature sensing (DTS) has been used for fracture parameter diagnosis and flow profile monitoring. In this paper, we present a new model for predicting the temperature profile of two-phase flow multistage fractured horizontal wells in the tight oil reservoirs. The homogeneous reservoir flow/heat transfer model is extended to the tight oil reservoir-fracture-wellbore coupled flow/thermal model. The influence of SRV area on reservoir and wellbore is considered, and the Joule-Thomson effect, heat convection, heat conduction, and other parameters are introduced into the improved model. The temperature distributions of reservoir and wellbore with different production times, water cut, and locations of water entry are simulated. The simulated results indicate that the Joule-Thomson effect will cause wellbore temperature to rise; the temperature of fractures with more water production is significantly lower than that of other fractures, and the water outlet location can be judged according to the temperature change of the wellbore. By using the improved temperature prediction model, the DTS monitoring data of twophase flow multistage fractured horizontal well in the tight reservoir has been calculated and analyzed, and the accurate production profile has been obtained.
\end{abstract}

\section{Introduction}

Multifractured horizontal well is an effective method to improve the recovery of tight reservoir. Fracture diagnosis techniques, such as production logging, microseismic, and well test interpretation [1-3] are used to identify fluid inflow and estimate the overall level of fracture parameters in horizontal wells, but it is difficult to determine the contribution of the fracture along the wellbore and production profile. In recent years, distributed temperature sensing (DTS) has been gradually used in downhole temperature monitoring. DTS provides continuous temperature profile data of fractured horizontal wells, and inversion of the measured data can interpret the fracture contribution and parameters $[4,5]$. DTS has high temperature resolution, which can reach $0.01^{\circ} \mathrm{C}$, so small temperature changes in the wellbore can be detected [6]. Accurate multistage fractured horizontal well temperature profile model is the basis of DTS data inversion. Ramey [7] first proposed the classical single-phase incompressible injection/production process wellbore temperature distribution prediction model, which solved the basic problem of wellbore heat transfer. The researchers have extended Ramey's theory to calculate transient and multiphase flow in different types of wells [8-10]. Different from vertical wells, horizontal well temperature profile changes very little and is mainly controlled by a series of microthermal effects such as the Joule-Thompson effect, heat conduction, and heat convection. Yoshioka et al. [11] established a steady-state temperature model for horizontal wells in a box homogeneous reservoir considering the Joule-Thomson effect, heat convection, and heat conduction. Izgec et al. [12] proposed an unsteady semianalytical temperature model to calculate the wellbore temperature distribution during production or shut-in. It is believed that the wellbore and reservoir temperature would change with the progress of production. Muradov and Davies [13] derived a single-phase (oil or water) steady-state temperature model for horizontal wells, and the microthermal effect fluid was considered in the model.

Hydraulic fracturing changes the initial temperature of the horizontal well and makes the fluid flow more complicated as fracturing fluid enters the formation. Cui et al. [14] 


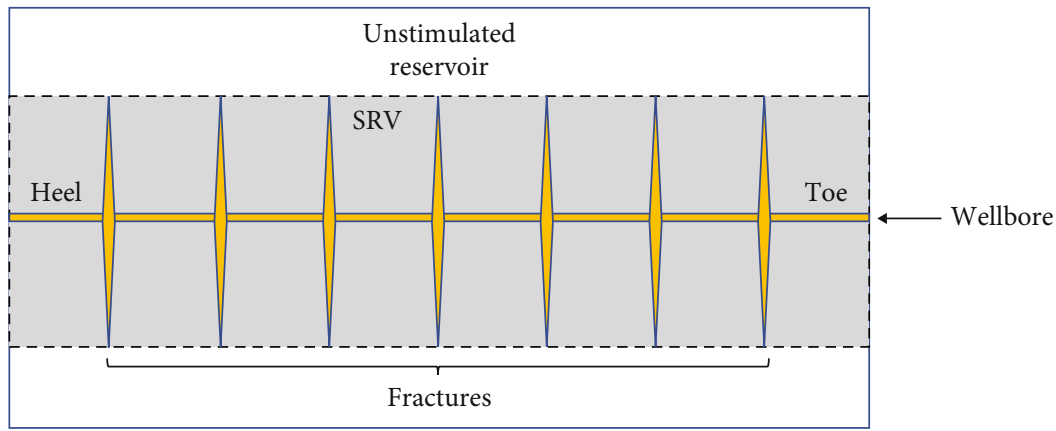

FIgURe 1: Physical model of multistage fractured horizontal well in tight oil reservoir.

established a computational model of hydraulic fracture temperature distribution based on the trilinear flow hypothesis, in which the Joule-Thomson effect and small temperature changes caused by frictional heat generation were considered. Yoshida [15] established a temperature prediction model for fractured horizontal wells in a single-phase gas reservoir and proposed that horizontal well temperature monitoring can help diagnose the parameters of fractures. Sui et al. [16] established a semianalytical reservoir-wellbore coupled thermal model for the tight gas reservoir, by considering open hole packer completion. Cao et al. [17] proposed a thermohydraulic coupling mathematical model to describe the temperature and pressure fields for multistage fractured horizontal wells (MFHWs) during the single-phase oil production process. However, few two-phase flow multistage fracturing horizontal well temperature prediction model is proposed in the tight reservoir.

In this paper, a coupled temperature model of fracturewellbore in a two-phase flow tight reservoir is established. The effects of the Joule-Thomson effect, heat convection, and heat conduction on wellbore temperature of multistage fractured horizontal wells are considered in the model. The variations of wellbore temperature at different production times, water cut, and locations of water entry are analyzed. Taking a horizontal well in a tight oil reservoir as an example, the temperature profile and the production profile of the horizontal well have been obtained.

\section{Mathematical Model Description}

2.1. Basic Assumptions. The stimulated reservoir volume (SRV) zone is formed after multistage fracturing of horizontal wells in tight oil reservoirs. In this area, the reservoir rocks are broken, forming hydraulic fractures and fracture areas $[18,19]$. In Figure 1, each fracture zone is simplified as a main fracture and a fracturing zone around the main fracture, in which the fracturing zone is simplified as a rectangular zone.

In this paper, according to the following assumptions: (1) the fluid is oil-water two-phase, slightly compressible, and conforms to Darcy's law; (2) the properties of each fracture remain unchanged; (3) fixed length and width of hydraulic fracture and unlimited diversion; and (4) the skin and wellbore-storage are negligible.
2.2. Coupled Model. Based on the assumptions above, the mass conservation equation of oil-water two-phase is obtained:

$$
-\nabla \cdot\left(\rho_{\beta} \vec{v}_{\beta}\right)=\frac{\partial}{\partial t}\left(\phi \rho_{\beta} S_{\beta}\right) .
$$

According to Darcy's Law:

$$
\vec{v}_{\beta}=-\frac{k k_{r \beta}}{\mu_{\beta}}\left(\nabla p_{\beta}-\rho_{\beta} g\right) .
$$

In Eq. (2), $k$ is permeability, $k_{r}$ is relative permeability, $\mu$ is dynamic viscosity, $\rho$ is density, and the subscript $\beta$ is oil or water. $\gamma$ is the degree of wellbore opening $(\gamma=1$ at fracture and $\gamma=0$ at cementing section). The temperature model of the oil reservoir has been given in previous issues $[15,20]$. It can be extended to the tight oil reservoir:

$$
\begin{aligned}
& \sum_{\alpha} \rho C_{p} \frac{\partial T}{\partial t}-\sum_{\alpha}\left(\phi S_{\alpha} \beta_{\alpha} \frac{\partial p_{\alpha}}{\partial t}\right) T \\
& =\sum_{\alpha}\left(\rho_{\alpha} \frac{\sigma_{\alpha} k k_{\alpha}}{\mu_{\alpha}} \cdot C_{p \alpha} \nabla p_{\alpha}\right) \nabla T \\
& \quad-\sum_{\alpha}\left\{\frac{\sigma_{\alpha} k k_{\alpha}}{\mu_{\alpha}}\left(\beta_{\alpha} T-1\right) \cdot\left(\nabla p_{\alpha}\right)^{2}\right\}+K_{T} \cdot \nabla^{2} T .
\end{aligned}
$$

In Eq. (3), from left to right, respectively, represent the internal energy change term in the reservoir, the energy change term caused by fluid thermal expansion, heat convection term, thermal expansion term and viscous dissipation term, heat conduction, and heat transfer between reservoir and wellbore.

Similarly, the fracture heat transfer model can be obtained:

$$
\begin{aligned}
\sum_{\alpha} \rho C_{p} & \frac{\partial T_{F}}{\partial t}-\sum_{\alpha}\left(\phi_{F} S_{F \alpha} \beta_{F \alpha} \frac{\partial p_{F \alpha}}{\partial t}\right) T_{F} \\
= & \sum_{\alpha} \frac{\rho_{F \alpha} \sigma_{F \alpha} k_{F} k_{F r \alpha} C_{F p \alpha}}{\mu_{\alpha}}\left(\frac{\partial p_{F \alpha}}{\partial x} \frac{\partial T_{F}}{\partial x}+\frac{\partial p_{F \alpha}}{\partial z} \frac{\partial T_{F}}{\partial z}\right) \\
& -\sum_{\alpha}\left\{\frac{\sigma_{F \alpha} k_{F} k_{F r \alpha}}{\mu_{\alpha}}\left(\beta_{F \alpha} T_{F}-1\right)\left[\left(\frac{\partial p_{F \alpha}}{\partial x}\right)^{2}+\left(\frac{\partial p_{F \alpha}}{\partial z}\right)^{2}\right]\right\} \\
& +K_{T F}\left(\frac{\partial^{2} T_{F}}{\partial y^{2}}+\frac{\partial^{2} T_{F}}{\partial z^{2}}\right) .
\end{aligned}
$$


In Eq. (4), subscript $F$ represents fracture parameters, and $k_{F}$ and $S_{F}$ represent permeability and saturation in fracture, respectively.

Based on the principle of energy conservation, the wellbore thermal model is established to describe the temperature distribution along the wellbore. For two-phase wellbore flow, the interaction between phases is ignored [21].

$$
\begin{aligned}
\frac{d T}{d x}= & \frac{d p}{d x} \frac{\sum_{\alpha} \rho_{\alpha} v_{\alpha} y_{\alpha} C_{p, \alpha} K_{J T, \alpha}}{\sum_{\alpha} \rho_{\alpha} v_{\alpha} y_{\alpha} C_{p, \alpha}} \\
& +\frac{2}{R}\left(T_{I}-T\right)\left[\frac{\gamma \sum_{\alpha} \rho_{\alpha, I} v_{\alpha, I} y_{\alpha, I} C_{p, \alpha}+(1-\gamma) \alpha_{T}}{\sum_{\alpha} \rho_{\alpha} v_{\alpha} y_{\alpha} C_{p, \alpha}}\right] \\
& -\frac{\sum_{\alpha} \rho_{\alpha} v_{\alpha} y_{\alpha}}{\sum_{\alpha} \rho_{\alpha} v_{\alpha} y_{\alpha} C_{p, \alpha}} g \sin \theta .
\end{aligned}
$$

The wellbore diameter is much smaller than the mesh size, and the flow and heat exchange between the wellbore and the reservoir grid block cannot be described directly in the mesh containing the wellbore. Therefore, the equivalent radius $r_{\text {eff }}$ is introduced to describe the flow between the reservoir grid block and the wellbore in the coupled model [22].

$$
r_{\text {eff }}=0.28 \frac{\left[\left(k_{y} / k_{x}\right)^{1 / 2} \Delta x^{2}+\left(k_{x} / k_{y}\right)^{1 / 2} \Delta y^{2}\right]}{\left(k_{y} / k_{x}\right)^{1 / 4}+\left(k_{x} / k_{y}\right)^{1 / 4}} .
$$

\section{Parameter Analysis}

In this section, the presented temperature profile prediction model of the multistage fractured horizontal well was used to analyze the wellbore temperature changes with different production time, water cuts, and locations of water entry.

This example considers a multistage fractured horizontal well with four transverse fractures in a tight reservoir. The fracture and calculation parameters are shown in Table 1.

3.1. Effect of Production Time. It is assumed that the well is produced at a constant oil production rate of $60 \mathrm{~m}^{3} / \mathrm{d}$ and the water production rate of $10 \mathrm{~m}^{3} / \mathrm{d}$. Figure 2 presents that the reservoir pressure and temperature distribution after 6 hours. Reservoir pressure and temperature decrease obviously at the fracture position, showing the typical production characteristics of a multistage fractured horizontal well. Figure 3 shows that the wellbore temperature rises with the production time increases, due to the production pressure difference causing the Joule-Thomson effect. In the oilwater production well, the Joule-Thomson effect of oil and water is different; the inflow of formation water will lower than the wellbore temperature. Thus, the temperature drop occurs, so the locations of formation water entering the wellbore can be identified.

3.2. Influence of Water Cut. The temperature profiles with different water cut values have been shown in Figure 4. From this data, we can see that with the increase in water production, the wellbore temperature profile decreases.
TABLE 1: The fracture and calculation parameters for analysis.

\begin{tabular}{lcc}
\hline Parameter & Unit & Value \\
\hline Formation porosity & - & 0.1 \\
Formation permeability & $\mathrm{mD}$ & 0.1 \\
Formation temperature & ${ }^{\circ} \mathrm{C}$ & 91 \\
Initial reservoir pressure & $\mathrm{MPa}$ & 20.3 \\
Rock heat capacity & $\mathrm{J} /\left(\mathrm{kg} \cdot{ }^{\circ} \mathrm{C}\right)$ & 1264 \\
Rock heat conductivity & $\mathrm{W} /\left(\mathrm{m} \cdot{ }^{\circ} \mathrm{C}\right)$ & 1.3 \\
Oil density & $\mathrm{kg} / \mathrm{m}^{3}$ & $0.641 \times 10^{3}$ \\
Oil viscosity & $\mathrm{cP}$ & 0.8 \\
Oil specific heat & $\mathrm{J} /\left(\mathrm{kg} \cdot{ }^{\circ} \mathrm{C}\right)$ & 2193 \\
Oil thermal conductivity & $\mathrm{W} /\left(\mathrm{m} \cdot{ }^{\circ} \mathrm{C}\right)$ & 3.46 \\
Water density & $\mathrm{kg} / \mathrm{m}^{3}$ & $1.0 \times 10^{3}$ \\
Water viscosity & $\mathrm{cP}$ & 0.317 \\
Water heat capacity & $\mathrm{J} /\left(\mathrm{kg} \cdot{ }^{\circ} \mathrm{C}\right)$ & 4194 \\
Water heat conductivity & $\mathrm{W} /\left(\mathrm{m} \cdot{ }^{\circ} \mathrm{C}\right)$ & 4.32 \\
Wellhead temperature & ${ }^{\circ} \mathrm{C}$ & 14.7 \\
Wellbore length & $\mathrm{m}$ & 800 \\
Pipe inner & $\mathrm{m}$ & 0.01 \\
Steel heat conductivity & $\mathrm{W} /\left(\mathrm{m} \cdot{ }^{\circ} \mathrm{C}\right)$ & 47 \\
Steel heat capacity & $\mathrm{J} /\left(\mathrm{kg} \cdot{ }^{\circ} \mathrm{C}\right)$ & 462.34 \\
Fracture permeability & $\mathrm{mD}$ & 2 \\
Fracture half length & $\mathrm{m}$ & 60 \\
Fracture width & $\mathrm{m}$ & 0.002 \\
\hline
\end{tabular}

The water-producing zone is indicated by the cool temperature anomaly in the fractures, with the beginning of the water zone corresponding to the sudden drop in temperature and the end of the water zone marked by the increase in temperature. For the higher water cut, this difference is more pronounced.

3.3. Impact of Water Entry. According to the data in Table 2, the temperature profiles of different locations of water entry are calculated. Figure 5 shows the fracture temperature distribution after 6 hours of production. Figure 5(a) shows that the water flows evenly from four fractures, and Figure 5(b) shows that more water entry from the heel end and toe end. Comparing the two results, it can be seen that the more water there is, the lower the temperature of the fracture. Figure 6 shows the wellbore temperature profiles in the two cases. It is apparent from this figure that the larger the water inflow, the faster the temperature drop of the fracture, and the heat conduction between fluids is greater than the influence of Joule-Thomson effect on the temperature. Therefore, the location and quantity of water entry can be determined by the wellbore temperature profile.

\section{Field Application}

The temperature prediction model of multistage fracturing horizontal well with the oil-water two-phase flow can be used to calculate the wellbore temperature at the stage of 
Pressure $(\mathrm{MPa})$
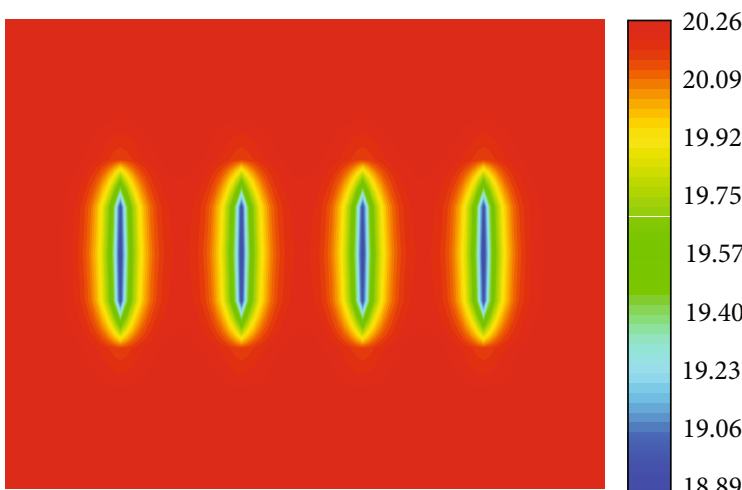

(a) Transient reservoir pressure distribution

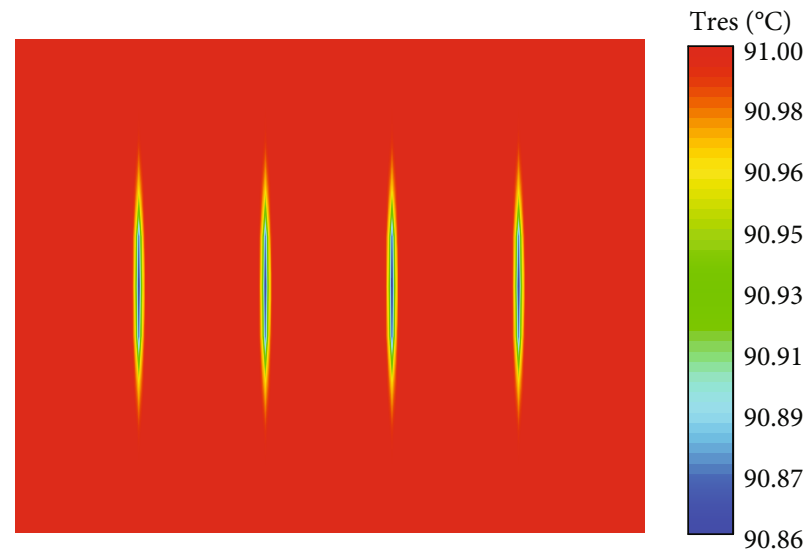

(b) Transient reservoir temperature distribution

FIGURE 2: Transient reservoir pressure and temperature distribution.

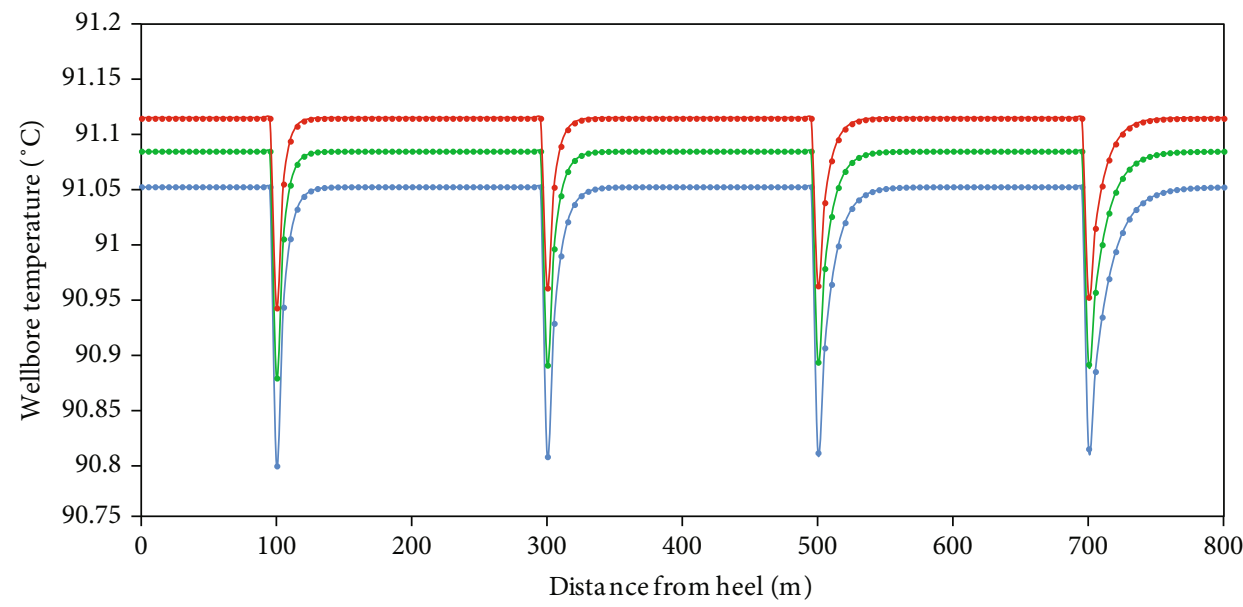

$\rightarrow 2 \mathrm{~h}$

$\rightarrow 6 \mathrm{~h}$

$\rightarrow 12 \mathrm{~h}$

FIgURE 3: Transient wellbore temperature profile.

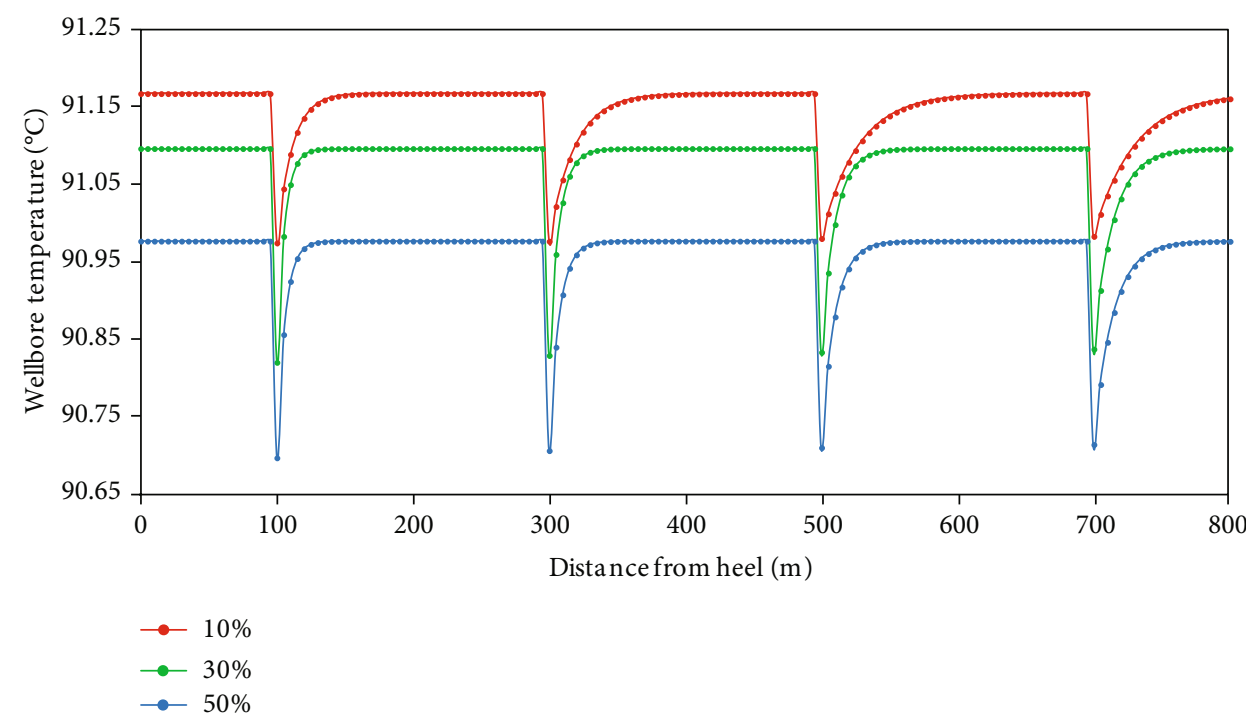

FIGURE 4: Wellbore temperature profile with different water cut values. 
TABLE 2: Fracture flow along the wellbore.

\begin{tabular}{lcccc}
\hline Oil and water rate $\mathrm{m}^{3} / \mathrm{m}^{3}$ & Frac1 & Frac2 & Frac3 & Frac4 \\
\hline Case 1 & $9.858 / 4.899$ & $9.993 / 4.991$ & $10.035 / 4.998$ & $10.114 / 5.112$ \\
Case 2 & $7.134 / 7.991$ & $12.654 / 2.843$ & $12.884 / 3.132$ & $7.328 / 7.034$ \\
\hline
\end{tabular}

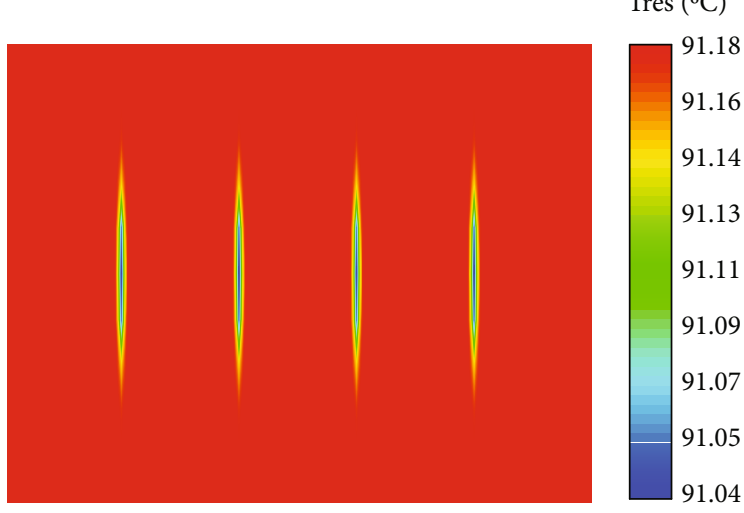

(a) Temperature distribution—case 1

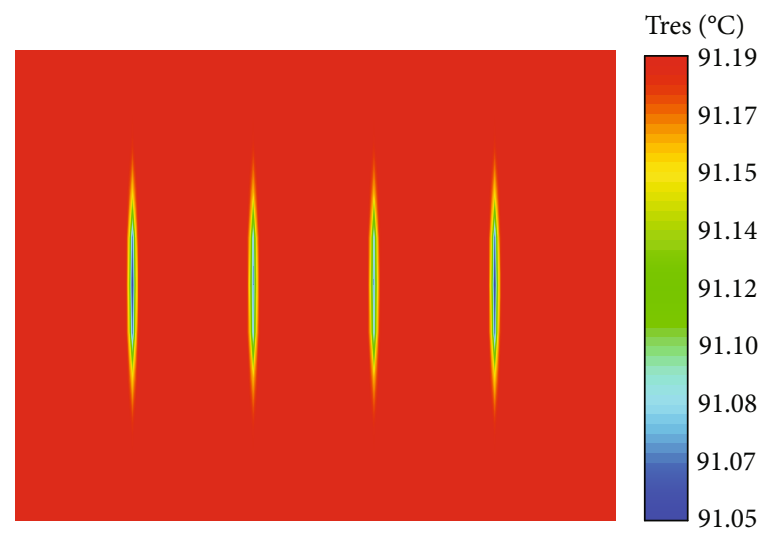

(b) Temperature distribution-case 2

FIgURE 5: Temperature distribution in the reservoir after 6 hours production.

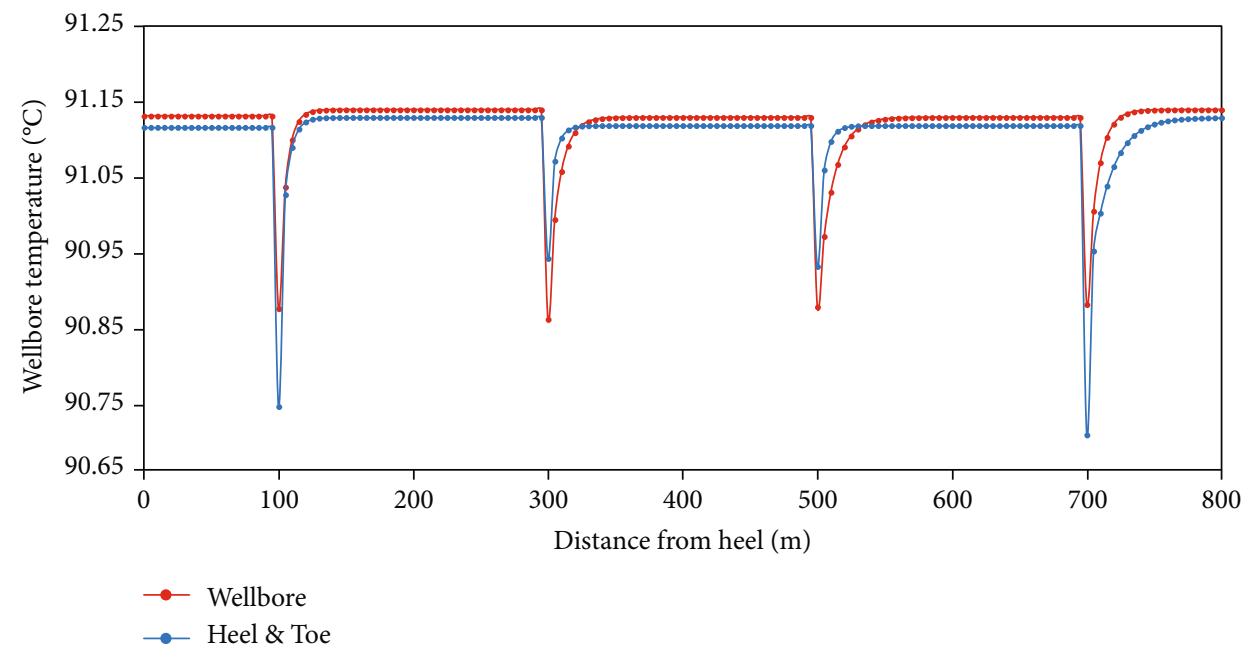

Figure 6: Wellbore temperature distribution after 6 hours production.

backflow. In this section, the model is applied to a tight oil fracturing horizontal well monitored by DTS, and a corresponding production profile is obtained. The well has 13stage fractured with DTS monitoring data from the 4 th to 13th stage fractures (the points at the bottom of the figures indicate the location of the wellbore covered by DTS). As shown in Figure 7, the wellbore temperature stabilizes gradually with the extension of shut-in time. The wellbore temperature of the 4 th, 5th, 7th, 11th, 12th, and 13th fracture sections decreased obviously under the influence of in situ fracturing fluid.

After the shut-in stage, the well is produced with a $5 \mathrm{~mm}$ nozzle, the average fluid rate is $50 \mathrm{t} / \mathrm{d}$, and the average water cut is $17.9 \%$. Figure 8 shows the wellbore temperature curves of the shut-in for $6 \mathrm{~h}$ and open production for $2 \mathrm{~h}, 4 \mathrm{~h}$, and $6 \mathrm{~h}$. It can be seen from the diagram that the wellbore temperature rises to the shut-in temperature due to the production pressure difference (Joule-Thompson effect) in the production of the horizontal well. In the 4 th, 5 th, 7 th, 11 th, 12 th, and 13th stages, the wellbore temperature curve is concave, which indicates that fractured fluid production entry in each stage above.

The well trajectory, completion structure, geothermal gradient, reservoir, wellbore parameters, and fluid properties are input into the model, and the DTS data of $12 \mathrm{~h}$ production are selected for simulation. The DTS data and model 


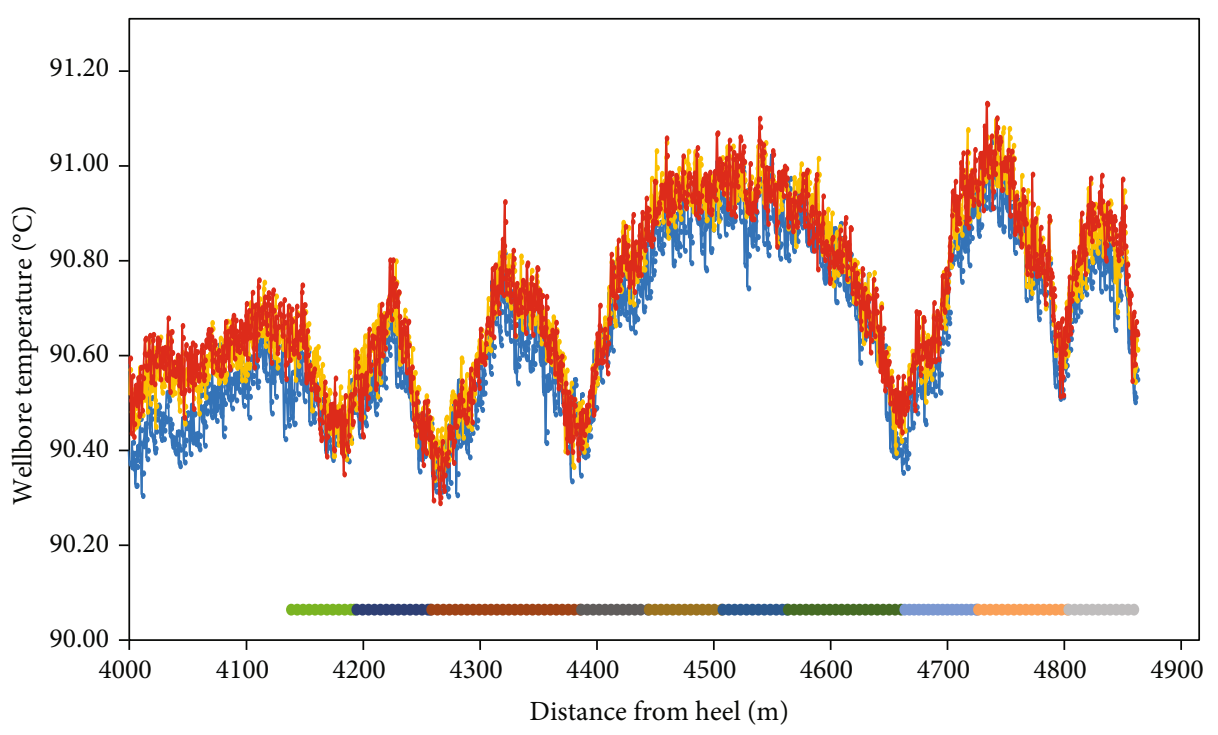

- - Shut-in for 2 hours

- $\rightarrow$ Shut-in for 4 hours

$\rightarrow$ Shut-in for 6 hours

FIGURE 7: Wellbore temperature profile at shut-in stage.

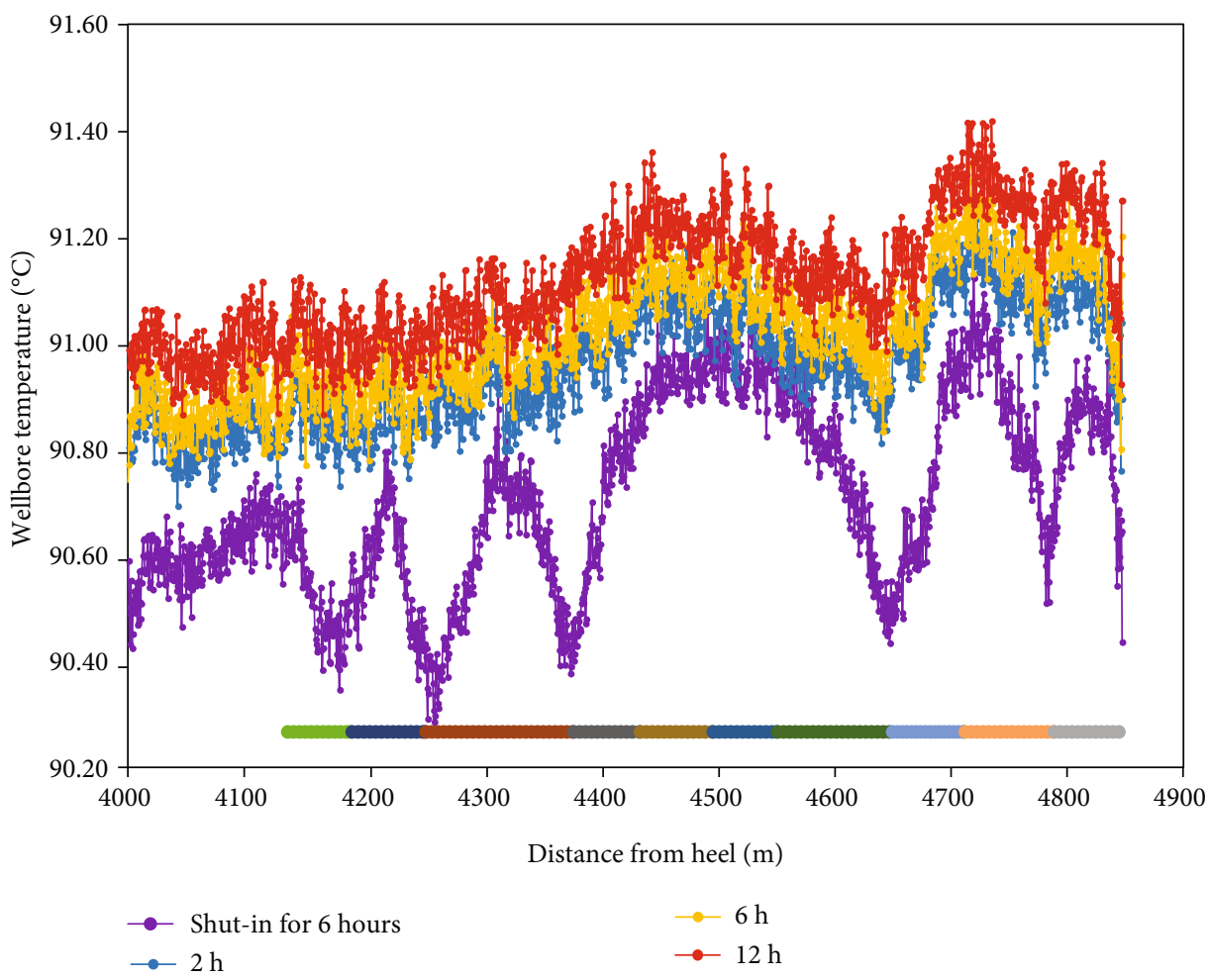

FIgURE 8: Wellbore temperature profile at different production times.

calculation results are shown in Figure 9. From this data, we can see that the fitting temperature at the 4 th stage fracture is lower than the measured temperature because the fracture is at the toe of the horizontal section, and there is still a section of the wellbore which has not been monitored. Based on the temperature fitting results, the wellbore production profile can be calculated as shown in Figure 10. Figure 10 shows that the water produced between the 7 th and 11th stage fractures is more than that from other fractures.

\section{Conclusion}

A two-phase wellbore temperature prediction model for multistage fractured horizontal wells in tight reservoirs is 


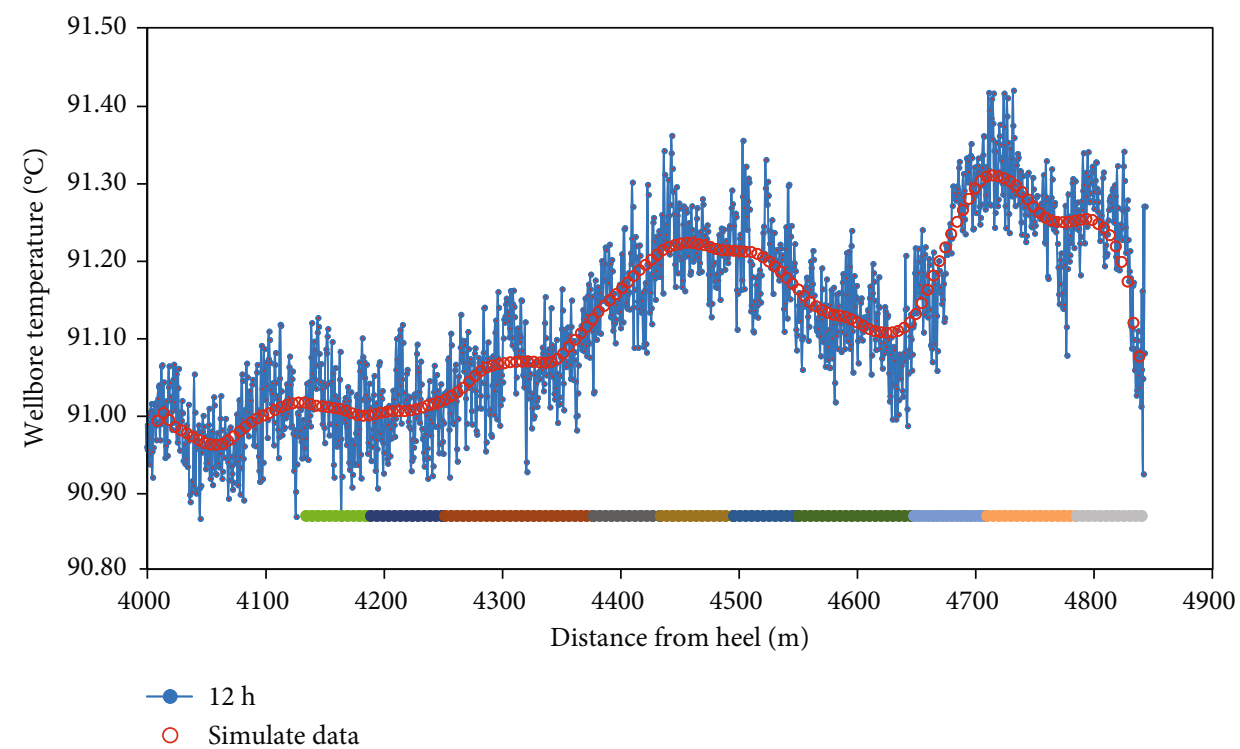

FIGURE 9: Measured temperature profile and model fitting results.

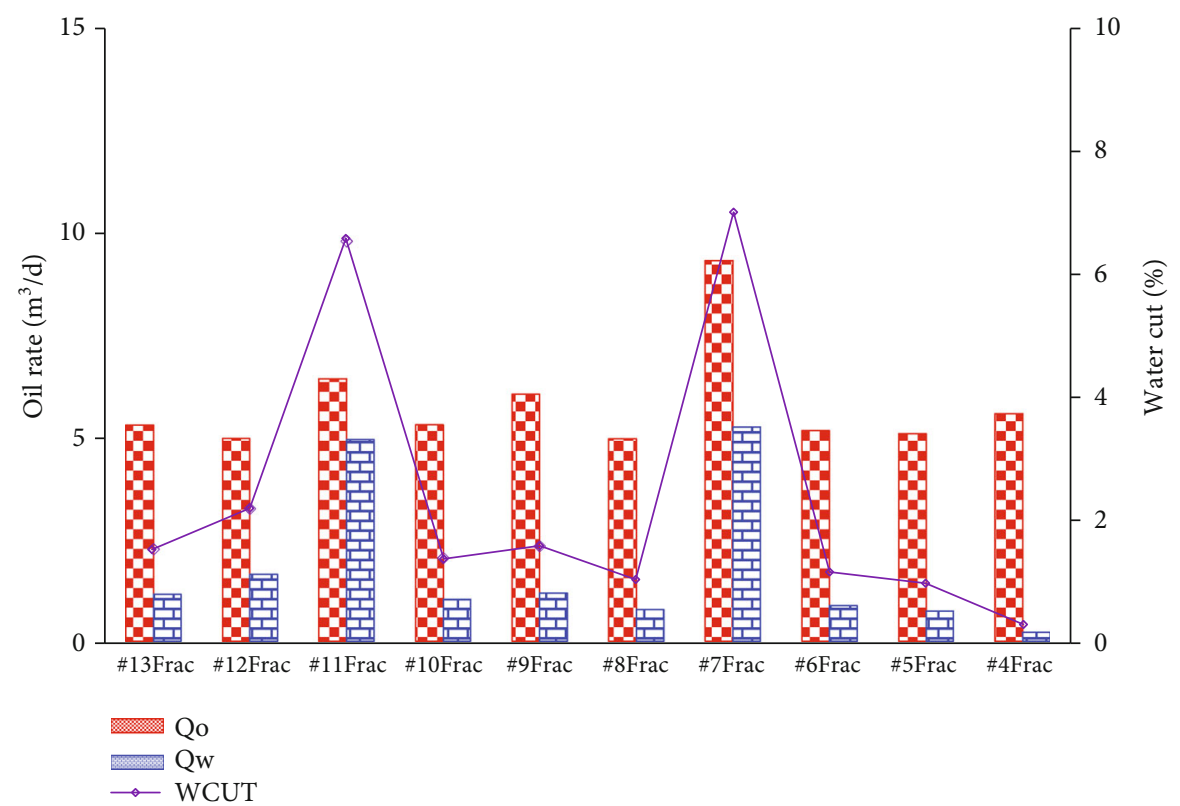

FIgURE 10: Oil and water rate profile inverted from DTS data.

established. Based on the simulation results and analysis, the main conclusions are summarized as follows: (1) in the production process, the Joule-Thomson effect will cause the wellbore temperature rise. With the development of production, the wellbore temperature gradually rises; (2) due to the different Joule Thomson coefficients of oil and water, the temperature of fracturing fluid is lower than that of crude oil, so when the fracture produces water, the wellbore temperature will drop, and the more the water, the lower the temperature. At this time, the heat conduction is the main factor affecting the wellbore temperature; (3) according to the simulation results, the more water produced, the lower the temperature at the fracture, so the location of formation water entering the wellbore can be identified.

\section{Data Availability}

The data used in this article are all from the actual monitoring data of the oil field.

\section{Conflicts of Interest}

The authors declare that they have no conflicts of interest.

\section{Acknowledgments}

This article was supported by the National Nature Science Foundation of China (No. 51904254) and the scientific research starting project of SWPU (No. 2018QHZ001). 


\section{References}

[1] A. Basov, B. Oleg, K. Vadim et al., "Evaluating performance of horizontal wells using integrated approach: micro seismic monitoring, geophysical logging using conventional PLT and marker-based production logging," in Paper presented at the SPE Annual Caspian Technical Conference, Baku, Azerbaijan, 2019.

[2] Y. Wang, J. Yang, J. Chen, and J. Song, “Adaptive finite element-discrete element analysis for the multistage supercritical $\mathrm{CO}_{2}$ fracturing and microseismic modelling of horizontal wells in tight reservoirs considering pre-existing fractures and thermal-hydro-mechanical coupling," Journal of Natural Gas Science and Engineering, vol. 61, pp. 251-269, 2019.

[3] Y. He, J. Qin, S. Cheng, and J. Chen, "Estimation of fracture production and water breakthrough locations of multi- stage fractured horizontal wells combining pressure-transient analysis and electrical resistance tomography," Journal of Petroleum Science and Engineering, vol. 194, p. 107479, 2020.

[4] E. H. Holley, M. M. Molenaar, E. Fidan, and B. Banack, "Interpreting uncemented multistage hydraulic-fracturing completion effectiveness by use of fiber-optic DTS injection data," SPE Drilling \& Completion, vol. 28, no. 3, pp. 243-253, 2013.

[5] S. Y. Shtun, A. A. Senkov, O. I. Abramenko et al., "The comparison of inflow profiling technologies for ERD wells including PLT, fiber optics DTS, stationary chemical tracers: a case study from the Caspian offshore Yuri Korchagin Field in Russia," in SPE Annual Caspian Technical Conference and ExhibitionSociety of Petroleum Engineers.

[6] A. Ukil, H. Braendle, and P. Krippner, "Distributed temperature sensing: review of technology and applications," IEEE Sensors Journal, vol. 12, no. 5, pp. 885-892, 2012.

[7] H. J. Ramey, "Wellbore heat transmission," Journal of Petroleum Technology, vol. 14, no. 4, pp. 427-435, 1962.

[8] I. N. Alves, F. J. S. Alhanati, and O. Shoham, "A unified model for predicting flowing temperature distribution in wellbores and pipelines," SPE Production Engineering, vol. 7, no. 4, pp. 363-367, 1992.

[9] A. R. Hasan and C. S. Kabir, "Aspects of wellbore heat transfer during two-phase flow (includes associated papers 30226 and 30970)," SPE Production \& Facilities, vol. 9, no. 3, pp. 211216, 1994.

[10] J. Hagoort, "Ramey's wellbore heat transmission revisited," SPE Journal, vol. 9, no. 4, pp. 465-474, 2004.

[11] K. Yoshioka, D. Zhu, A. D. Hill, P. Dawkrajai, and L. W. Lake, "A comprehensive model of temperature behavior in a horizontal well," in SPE annual technical conference and exhibitionOnePetro.

[12] B. Izgec, C. S. Kabir, D. Zhu et al., "Transient fluid and heat flow modeling in coupled wellbore/reservoir systems," SPE Reservoir Evaluation \& Engineering, vol. 10, no. 3, pp. 294301, 2007.

[13] K. Muradov and D. Davies, "Novel analytical methods of temperature interpretation in horizontal wells," in SPE Europec featured at EAGE Conference and Exhibition, 2010.

[14] J. Cui, C. Yang, D. Zhu, and A. Datta-Gupta, "Fracture diagnosis in multiple-stage-stimulated horizontal well by temperature measurements with fast marching method," SPE Journal, vol. 21, no. 6, pp. 2289-2300, 2015.

[15] N. Yoshida, Modeling and Interpretation of Downhole Temperature in a Horizontal Well with Multiple Fractures, Texas A \& M University, 2016.
[16] W. Sui, D. Zhang, S. Cheng, Q. Zou, F. Xiaosong, and Z. Ma, "Improved DTS profiling model for horizontal gas wells completed with the open- hole multi-stage fracturing system," Journal of Natural Gas Science and Engineering, vol. 84, p. 103642, 2020.

[17] Z. Cao, P. Li, Q. Li, and L. Detang, "Integrated workflow of temperature transient analysis and pressure transient analysis for multistage fractured horizontal wells in tight oil reservoirs," International Journal of Heat and Mass Transfer, vol. 158, p. 119695, 2020.

[18] X. Z. Li, D. T. Lu, R. L. Luo et al., "Quantitative criteria for identifying main flow channels in complex porous media," Petroleum Exploration and Development, vol. 46, no. 5, pp. 998-1005, 2019.

[19] W. J. Shen, F. Q. Song, X. Hu, G. M. Zhu, and Y. W. Zhu, "Experimental study on flow characteristics of gas transport in micro- and nanoscale pores," Scientific Reports, vol. 9, no. 1, 2019.

[20] P. M. J. Tardy, P. Ramondenc, X. Weng, R. Burgos, F. Baez, and K. Yekta-Ganjeh, "Inversion of distributed-temperature sensing logs to measure zonal coverage during and after wellbore treatments with coiled tubing," SPE Production \& Operations, vol. 27, no. 1, pp. 78-86, 2012.

[21] A. S. Ramazanov and V. M. Nagimov, "Analytical model for the calculation of temperature distribution in the oil reservoir during unsteady fluid inflow," Oil and Gas Business Journal, vol. 1, no. 1, pp. 1-8, 2007.

[22] D. W. Peaceman, "Interpretation of well-block pressures in numerical reservoir simulation (includes associated paper 6988)," Society of Petroleum Engineers Journal, vol. 18, no. 3, pp. 183-194, 1978. 